\title{
PRODUÇÃO DE PODCAST COMO METODOLOGIA ATIVA NO ENSINO-APRENDIZAGEM DE LITERATURA PORTUGUESA
}

\author{
Podcast Production as an Active Methodology \\ in the Teaching and Learning of Portuguese Literature
}

DOI: 10.14393/LL63-v37n1-2021-14

\author{
Alleid Ribeiro Machado* \\ Fernando Luis Cazarotto Berlezzi**
}

\begin{abstract}
RESUMO: O ensino deve se adaptar às mudanças na sociedade e às necessidades dos alunos para promover o seu objetivo maior: a aprendizagem. Nesse novo perfil tem se revelado a necessidade de conexões entre o hibridismo das comunicações diárias e os estudos interdisciplinares de literatura e cultura. O intuito é promover o processo de ensino-aprendizagem e a formação de leitores críticos afinados com a dinâmica da sociedade de informação e comunicação. Aliadas à cultura digital, as novas demandas trazidas pela Base Nacional Comum Curricular (BNCC/2018), que organiza o currículo da Educação Básica, estão implicadas na urgência da formação de professores com uma atenção voltada ao uso de diferentes linguagens, resultando no desenvolvimento de habilidades, competência e aprendizado do aluno. Diante do exposto, este artigo procura dialogar com tais necessidades ao trazer a experiência de trabalho em ambiente educacional no âmbito do ensino de Literatura Portuguesa e a produção de podcast.
\end{abstract}

PALAVRAS-CHAVE: Literatura Portuguesa. BNCC. Podcast. Ensino-aprendizagem. Metodologias ativas.

ABSTRACT: Teaching must adapt to changes in society and the needs of students to promote its main objective: learning. This has urged for connections between the hybridity of daily communications and interdisciplinary studies of literature and culture. The aim is to promote the teaching-learning process and the education of critical readers in tune with the dynamics of the information and communication society. The new demands brought by the Brazilian Common Curriculum Framework released by the end of 2018 have been oriented to the digital age and have urged a teacher training focused on the use of different languages, resulting in the development of students' skills, competence, and learning. This article reports on an activity experienced by students and teachers of a postgraduate course in the context of teaching Portuguese Literature in the production of a podcast.

KEYWORDS: Portuguese literature. Brazilian Common Curriculum Framework. Podcast. Teachinglearning. Active methodologies.

\footnotetext{
* Doutora em Letras pela Faculdade de Filosofia, Letras e Ciências Humanas da Universidade de São Paulo. ORCID: 0000-0001-9359-532X. E-mail: alleid(AT)alumni.usp.br .

** Doutorando em Letras pela Universidade Presbiteriana Mackenzie. ORCID: 0000-0002-3421-2277. Email: fernando(AT)berlezzi.com.
} 


\section{Introdução}

A Base Nacional Comum Curricular (2018) define os direitos e as aprendizagens dos alunos de todo o Brasil. É um documento obrigatório, que orienta as competências gerais das áreas do saber que todos os alunos devem aprender na Educação Básica. Além das áreas de conhecimentos específicas, a BNCC apresenta também 10 competências que devem evoluir da Educação Infantil para o Ensino Médio e que foram definidas a partir dos direitos éticos, estéticos e políticos assegurados pelas Diretrizes Curriculares Nacionais (2010) e dos conhecimentos, habilidades, atitudes e valores essenciais para a vida no século XXI. São elas: conhecimento; pensamento científico, crítico e criativo; repertório cultural; comunicação; cultura digital; trabalho e projeto de vida; argumentação; autoconhecimento e autocuidado; empatia e cooperação; responsabilidade e cidadania (BRASIL, 2018).

As orientações do referido documento impactam diretamente na sala de aula, expondo os conhecimentos adequados para cada turma e cada modalidade. Atua de forma positiva ao não engessar a prática docente, possibilitando a construção de um currículo local. Em outras palavras, a partir das orientações apresentadas pela BNCC, cada escola constrói seu currículo atendendo os direitos de aprendizagem, respeitando a realidade e a cultura de sua região.

Vale também lembrar que a BNCC divide e apresenta os conteúdos a serem trabalhados para cada nível da Educação Básica, tendo como foco a formação do aluno para os diversos usos da linguagem e para uma participação mais ativa na sociedade de maneira crítica e ativa. A BNCC (2018) refere-se ao estudo de textos em múltiplas linguagens, incluindo as digitais, levando protagonismo aos alunos, sendo clara quanto à necessidade de contextualizar as práticas de linguagem.

A partir desse cenário, o texto (escrito e elaborado pelo aluno-aprendiz) assume a centralidade da unidade de trabalho, devendo estar associado ao contexto de sua aprendizagem. A ideia é que haja "significado" quanto ao uso da linguagem em atividades de leitura, de escuta, de produção em diversas situações. (BRASIL, 2018, p. 65). Ampliando mais um pouco este pressuposto trazido pela BNCC, podemos dizer que a produção textual se desdobra em práticas de linguagem, tais como a escrita compartilhada e autônoma, cujo 
objeto de conhecimento é a escrita colaborativa. No caso, por exemplo, de uma turma de 5o ano do Ensino Fundamental, essa atividade deve consistir em "(EF05LP17) Produzir roteiro para edição de uma reportagem digital sobre temas de interesse da turma, a partir de buscas de informações, imagens, áudios e vídeos na internet, de acordo com as convenções do gênero e considerando a situação comunicativa e o assunto/tema do texto" (BRASIL, 2018, p. 125).

Prosseguindo na discussão, a BNCC traz como proposta o trabalho da linguagem, assumindo "a centralidade do texto como unidade de trabalho e as perspectivas enunciativo-discursivas na abordagem, de forma a sempre relacionar os textos a seus contextos de produção e o desenvolvimento de habilidades ao uso significativo da linguagem em atividades de leitura, escuta e produção de textos em várias mídias e semioses" (BRASIL, 2018, p. 65). Como a textualidade tem sido concebida apenas como organização verbal, pouco tem sido percebido da expansão da escrita e de seus produtos; não se entende o texto como a combinatória de diferentes códigos: um produto híbrido. Um produto em aberto, em expansão, sendo tecido. Logo, é necessário "um olhar" mais atencioso para o movimento dos gêneros na cultura contemporânea (MACHADO, 1999).

Sabemos que o uso da escrita alfabética interfere na construção da linguagem audiovisual, ou seja, a linguagem escrita está disponível para colaborar na construção da imagem. Machado (2003) defende a ideia de que a compreensão da expansão da escrita exige que olhemos a nossa cultura como um conjunto de sistemas semióticos. Esses sistemas foram se constituindo num processo de modelização. Modelizar:

é construir sistemas de signos a partir do modelo de língua natural. Contudo, cada sistema desenvolve uma forma peculiar de linguagem e, no processo de descodificação do sistema modelizante não se volta para o modelo de língua, mas para o sistema que a partir dela foi construído. (MACHADO, 2003, p. 51)

Nesse sentido, concebemos a nossa cultura como uma grande rede, tecida pelos sistemas que estamos construindo. É nesse contexto que "enxergamos" a escrita num processo de expansão. Na construção de uma imagem audiovisual, as ideias expressas oralmente ou por escrito, ao serem recodificadas em imagem e som, sofrem sempre 
modificações. Essas modificações são provocadas pelas ações do homem, pelas máquinas e condições do código. Assim, compreender como a escrita perde sua dimensão e é modelizada pela linguagem audiovisual faz parte, nesse caso, do processo de construção dos filmes, cuja elaboração depende das conexões estabelecidas entre os códigos (sonoros, visuais e cinéticos). Logo, o conhecimento de tais códigos interfere na produção de textos audiovisuais.

Enxergar a imagem e escutar o som que será divulgado (a cena que será mostrada), no momento em que escreve o roteiro, assim como selecionar os elementos visuais e auditivos que servirão de referência para despertar o interesse do espectador, são passos importantes a considerar.

Vale lembrar que, ao aprendermos determinado conteúdo, como por exemplo, na área da produção audiovisual, a construção de filmes de animação, utilizamos conhecimentos já assimilados de outras linguagens, o que temos de disponível é requisitado para a aprendizagem de um novo conteúdo.

Tendo exposto a necessidade do professor se adaptar às mudanças na sociedade e às necessidades dos alunos para promover a aprendizagem, enfatizada na BNCC, este artigo traz para primeiro plano, a experiência de uma atividade vivenciada pelos alunos e docentes da disciplina de pós-graduação "Recursos teatrais no ensino-aprendizagem de Literatura Portuguesa" ministrada no segundo semestre de 2019 pelas Profa. Dra. Flavia Maria Corradin e Profa. Dra. Alleid Ribeiro Machado, disciplina credenciada junto ao Programa de Pós-Graduação em Literatura Portuguesa, no Departamento de Letras Clássicas e Vernáculas da Faculdade de Filosofia, Letras e Ciências Humanas, da Universidade de São Paulo (USP). Essa atividade foi objeto de apresentação e está publicada sob o título "Relato de Experiência: Produção audiovisual como metodologia ativa no ensino-aprendizagem de literatura portuguesa" no livro resultante das VII Jornadas de Literatura Portuguesa da FFLCH/ USP $(2019)^{1}$.

Sendo assim, a fim de tratarmos dessa atividade, vamos contextualizá-la ao lado dos objetivos da disciplina de pós-graduação em pauta: "a ideia era trazer pessoas que tivessem iniciativas significativas em educação para compartilhar. Que pudessem, a partir

\footnotetext{
${ }^{1}$ Berlezzi e Machado (2020).
} 
de relatos e oficinas, promover instrumentos didático-pedagógicos para melhor realização de uma aula e assim auxiliar-nos em nossas práticas" (BERLEZZI; MACHADO, 2020, p. 180). Na referida ocasião, observamos que havia muita coisa importante acontecendo e que precisavam ser realmente compartilhadas no âmbito da pós-graduação, como sabemos mais genericamente voltada para a pesquisa epistemológica e menos para a prática de sala de aula. Sendo assim,

Um destes encontros ocorreu na aula do dia 08/10/2019, quando tivemos o prazer de receber o Prof. Me. Fernando Luis Cazarotto Berlezzi da Universidade Presbiteriana Mackenzie, instituição em que ele também realiza o seu doutoramento, que ministrou a palestra seguida de oficina intitulada "Audiovisual: uma linguagem para a aprendizagem. Produzindo 'Audiovisual' como metodologia ativa no ensino-aprendizagem de literatura portuguesa." Neste dia, além de explanar acerca de intermidialidade e metodologias ativas, deteve-se mais especificamente no uso de recursos tecnológicos em Educação. Dessa forma, foi escolhido um recurso tecnológico para aprendermos a usar na oficina ora proposta: o podcast. Durante a realização de sua palestra, nasceu a ideia de fazermos uma série de Literatura Portuguesa em que vamos apresentando conteúdos relacionados tanto à história e cultura portuguesas quanto a sua literatura. Intitulamos esta série como 'Conhecendo Portugal'; e o primeiro episódio "Sobre a saudade" (BERLEZZI; MACHADO, 2020, p. 181)

Utilizamos como base para a formulação deste primeiro podcast o texto "Tempo português", de Eduardo Lourenço, que está publicado em seu livro Mitologia da saudade (Companhia das Letras, 1999). Neste processo, lançamos mão da metodologia ativa, na medida que tivemos um trabalho conjunto entre alunos e professores, além da intermidialidade, ou seja, da transposição do texto, passando pelo roteiro e finalmente o podcast produzido, numa nova mídia: o áudio.

\section{Pressupostos teóricos}

\subsection{Em torno das metodologias ativas de aprendizagem}

Todos os processos de aplicação de formas de ensinar podem ser entendidas como parte dos processos ligados às metodologias ativas. Considerando inevitavelmente a 
presença de um sujeito, protagonista do saber, as metodologias ativas são produzidas a partir do uso de ferramentas de ensino diversas, sob orientação de um professor/tutor.

Há muitas ferramentas de ensino que podem ser utilizadas dentro do campo das metodologias ativas, quais sejam: dramatização, nuvens de palavras, mapas mentais e conceituais, aulas invertidas, portfólio, estudo dirigido, solução de problemas, seminário, júri simulado, estudo de caso, dentre outras. $\mathrm{O}$ uso de podcast insere-se nesse amplo espectro de ferramentas, porém, seu uso pressupõe que se tenha à disposição um recurso tecnológico, podendo ser minimamente um smartphone. (BERLEZZI; MACHADO, 2020, p. 182)

As metodologias ativas são consideradas, atualmente, de grande relevância nos processos de ensino-aprendizagem, uma vez que proporcionam uma revisão nas formas de ensinar ao "habilitar os docentes para o uso de novas [e velhas] técnicas" (ANASTASIOU; ALVES, 2009, p. 13). Na contramão da ideia basilar de que cabe ao professor ensinar e ao aluno aprender, o que se propõe é uma visão de tarefas reguladas nas múltiplas aprendizagens e em sua consequente troca. Neste pressuposto, não ficam de fora ou "excluídas as historicidades, os determinantes, os nexos internos, a rede teórica, enfim, os elementos que possibilitaram aquela síntese obtida; a ausência desses aspectos científicos, sociais e históricos deixa os conteúdos soltos, fragmentados, com fim em si mesmos" (ANASTASIOU; ALVES, 2009, p. 13). Estamos diante da ressignificação do processo de ensinar, na qual as metodologias ativas entram como apoio fundamental. Nesse sentido, segundo Anastasiou e Alves (2009, p. 18):

Como outros verbos de ação, ensinar contém, em si, duas dimensões: uma utilização intencional e uma de resultado, ou seja, a intenção de ensinar e a efetivação dessa meta pretendida. Assim, se eu expliquei um conteúdo mas o estudante não se apropriou dele, posso dizer que ensinei ou apenas cumpre uma parte do processo? Mesmo tendo uma sincera intenção de ensinar, se a meta (a apreensão, a apropriação do conteúdo por parte do aluno) não se efetivou plenamente, como seria necessário ou esperado para prosseguir o caminho escolar do aluno, posso dizer que ensinei? Terei cumprido as duas dimensões pretendidas na ação de ensinar? 
Ao adotarmos a ideia de um trabalho que revê os processos de ensinoaprendizagem, estamos, sem dúvida alguma, abrindo mão, em certa medida, da nossa prática tradicional, que também é válida. Estamos, portanto, abrindo caminho para a utilização de ferramentas que proporcionarão uma nova dimensão ao ato de ensinar e ao de aprender, inserindo a nossa prática numa perspectiva que precisa estar alinhada ao bom senso nas escolhas do professor segundo os seus objetivos de trabalho em sala de aula.

Ressaltamos, porém, que essa nova perspectiva de ensinagem, que se faz "nessa superação da exposição tradicional como única forma de explicar os conteúdos" (ANASTASIOU; ALVES, 2009, p. 20), procura despertar o gosto do aluno pelo aprendizado, pois:

Trabalhando com os conhecimentos estruturados como saber escolar, é fundamental destacar o aspecto do saber referente ao gosto ou sabor, do latim sapere - ter gosto. Na ensinagem, o processo de ensinar e aprender exige um clima de trabalho tal que se possa saborear o conhecimento em questão. O sabor é percebido pelos estudantes quando o docente ensina determinada área que também saboreia, na lida cotidiana profissional e/ou na pesquisa, e a socializa com seus parceiros na sala de aula. Para isso, o saber inclui um saber o quê, um saber como, um saber por quê e saber para quê. (ANASTASIOU; ALVES, 2009, p. 20, grifo do autor)

Vale lembrar que as metodologias ativas de aprendizagem se inserem numa forma de ensino mais dialógica, sendo essencialmente voltadas para a transversalidade, interdisciplinaridade, multidisciplinaridade e pluralidade de aplicações de conteúdos, o que deve resultar numa reflexão mais ampla acerca dos conceitos estudados, mobilizando para a construção do conhecimento significação, problematização, práxis, criticidade, continuidade e ruptura, historicidade e totalidade (VASCONCELLOS, 1994).

Analisando o contexto atual, que se elabora a partir de mudanças e adaptações cada vez mais rápidas, é essencial:

revermos as nossas práticas docentes, buscando compreender essa nova realidade, interagindo ativamente com ela. Os nossos alunos, de um modo geral, os que pertencem as grandes massas urbanas, já trazem consigo essa expectativa de mudança. Como já afirmamos anteriormente, o uso das metodologias ativas de aprendizagem oferece uma possibilidade de trabalho cujo principal objetivo é estimular os alunos para que aprendam de maneira independente e colaborativa. A ideia é que o discente seja ativamente 
estimulado a estar no centro do processo de aprendizagem e, principalmente, que seja responsável pela construção de seu conhecimento. (BERLEZZI; MACHADO, 2020, p. 184)

É preciso então dizer, mediante a experiência vivenciada, que o uso do podcast na perspectiva das metodologias ativas "mobilizou-nos para uma ação efetiva do conteúdo, de modo que pudemos nos inserir exatamente no centro do processo de aprendizagem" (BERLEZZI; MACHADO, 2020, p. 184). No caso do trabalho com a literatura portuguesa, para que ele aconteça, é necessária uma adaptação do conteúdo do objeto a ser estudado. Aí que passamos para a explicação da intermidialidade.

\subsection{Intermidialidade}

Nesta pesquisa, "intermidialidade" é entendida como um processo de conjunção e o diálogo entre diferentes mídias, encontrando lugar como recurso didático no trabalho em espaços de escolarização. Definindo mais precisamente o conceito, trata-se de interrelação e interação entre mídias (CLÜVER, 2012, p. 9).

Clüver (2012) ainda destaca três maneiras fundamentais de interação entre as mídias, por meio das quais nos basearemos para observar de que maneiras a intermidialidade se apresenta no contexto de sala de aula.

Desse modo, há diferentes especificações:

[...] a combinação de mídias (por exemplo, em histórias em quadrinhos ou no grafite); referências intermidiáticas (por exemplo, ao teatro ou à pintura, em filmes) e a transposição midiática (por exemplo, na adaptação de romances para o cinema). (CLÜVER, 2012, p. 8)

Este trabalho valeu-se da intermidialidade, uma vez que, no caso específico das aulas de literatura portuguesa, buscamos fazer a migração de uma amostra desta literatura constante em alguns livros (mídia impressa) para o podcast (mídia digital áudio). E isso se fez graças a produção da escrita de um roteiro, uma mídia intermediária entre o texto original e o produto resultante deste processo. Nesse sentido, é importante salientar que o roteiro traduz os anseios do autor, denominado roteirista, e serve como um documento/mapa para o diretor e equipe de produção realizar determinado projeto. Este texto será trabalhado e poderá ser comprovado após a realização da pesquisa, ou seja, o 
roteiro pode ser considerado o guia para a concepção de qualquer produto audiovisual, sendo o seu objetivo alcançado quando "sai do papel" e se torna algo concreto, visível.

\section{Metodologia}

É preciso relatar as origens do termo, que foi utilizado por Adam Curry em 2004 a partir da abreviatura das palavras "public on demand" e broadcast. Na verdade, trata-se de um sistema de disponibilização de arquivo de áudio através da Internet que pode ser acessado por qualquer pessoa (BOTTENTUIT JUNIOR; COUTINHO, 2007).

Segundo Berlezzi e Machado (2020, p. 185), "essa tecnologia surgiu quando Curry (DJ da MTV) e Dave Winer (criador de software) criaram um programa que permitia descarregar automaticamente transmissões de rádio na Internet diretamente para os seus iPods". Os autores ainda lembram que:

Os podcasts se parecem com os tradicionais programas de rádios, mas seu ambiente é o meio digital e seu modo de distribuição se dá por "assinatura", isto é, as pessoas cadastradas recebem diretamente os arquivos em seus aparelhos (feed). Por isso usualmente o termo podcast, já tem se referido ao formato e/ou linguagem empregado num arquivo de áudio com diversas finalidades. [Além disso], eles têm sido utilizados em contextos educacionais pois confere mobilidade e flexibilidade para as aulas, além de poder ser facilmente produzido. Seu uso traz diferentes possibilidades de trabalho no processo de ensino/aprendizagem devido as suas características, podendo ir ao encontro das expectativas das novas gerações de alunos que chegam tanto no ensino básico quanto superior, ávidos a consumir e a produzir informações mediadas pela Internet. (BERLEZZI; MACHADO, 2020, p. 185)

Entretanto, o aumento de seu emprego como recurso de ensino talvez se deva "à sintonia que proporciona com os modos de comunicação atuais, na chamada Era Cibernética" (BERLEZZI; MACHADO, 2020, p. 186). Para Santaella, uma das principais características de tal "Era" pode ser resumida com a expressão "a cultura do acesso" (SANTAELLA, 2003, p. 28), isto é, comunicação on demand com grande empoderamento do receptor sobre o conteúdo da comunicação - escolhido e acessado por ele - assim como sobre onde ou quando recebê-lo, além das possibilidades de resposta ou comentário sobre o que foi comunicado. 
Diante do exposto, devemos ressaltar que é preciso seguir alguns critérios e considerar certas etapas para utilização deste importante recurso, como por exemplo a definição do escopo dos podcasts e sua amplitude; a seleção do conteúdo a ser desenvolvido a partir dos Planos de Ensino; a roteirização dos conteúdos².

Definido essa parte processual do podcast, a próxima etapa é decidir o tipo de serviço que irá hospedar o podcast: hoje em dia existem diversos provedores como Google. É importante ter certeza de que a proposta do projeto está de acordo com a plataforma tecnológica a ser usada. A terceira etapa, é a confeç̧ão do roteiro para o programa. Paralelamente faz-se a seleção de elementos como: músicas, vinheta, efeitos especiais, bordões etc. Dessa forma concebe-se os roteiros para o programa. A quarta etapa é gravação das locuções, das narrativas, das entrevistas e/ou das discussões. Depois procedese, na quinta etapa, à edição do programa, montando-se o material num único arquivo e transformando-o no formato final de arquivo, geralmente MP3. Finalmente, na sexta etapa, o material é disponibilizado na plataforma de distribuição escolhida. Uma sétima etapa seria a apropriação e utilização do arquivo de áudio por parte do usuário.

\section{Resultados e conteúdo apresentado}

A produção do podcast só foi possível por meio da efetiva participação dos docentes e discentes da disciplina "Recursos teatrais no ensino-aprendizagem de Literatura Portuguesa" (FFLCH/ USP), os quais estabeleceram fases para a sua execução. Algumas destas etapas podem ser descritas minimamente como a definição do objetivo dos podcasts; a elaboração e escrita de um roteiro a ser seguido; o ensaio a partir da leitura do roteiro; a gravação incluindo o processo de adaptação do roteiro; a edição do material elaborado; ideias e sugestões para a criação de um logo; definição de um local virtual para abrigar o arquivo (conforme figura abaixo) e, por fim, a apresentação do podcast produzido nas VII Jornadas de Literatura Portuguesa (FFLCH/ USP, 2019). Abaixo apresentamos o logo criado para o podcast "Conhecendo Portugal" e o endereço para acesso a esse material:

\footnotetext{
2 Para um estudo mais ampliado sobre os roteiros de produção do podcast, bem como a íntegra do que foi produzido, sugerimos a leitura de Berlezzi e Machado (2020).
} 

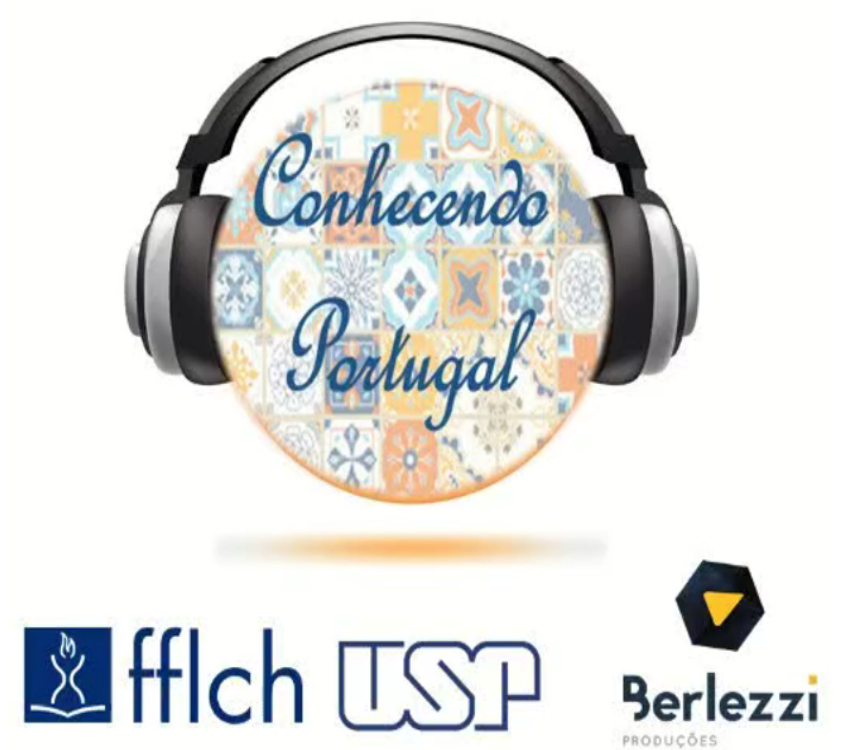

Figura 1: Logo do podcast "Conhecendo Portugal"

Fonte: elaborado pelo autor (disponível em bit.ly/podcastconhecendoportugal).

Em relação ao que foi elaborado, como já afirmamos anteriormente, lançamos mão do texto "Tempo português" de Eduardo Lourenço, publicado em seu livro Mitologia da saudade (Companhia das Letras, 1999), que foi narrado pela Profa. Flavia Corradin (FFLCH/ USP). Participaram também da leitura do conteúdo as professoras Alleid Ribeiro Machado e Marina Gialluca Domene, que recitaram poemas que exemplificam a fala do filósofo português. Já o Prof. Me. Fernando Luis Berlezzi ficou responsável pela gravação e edição do material.

\section{Considerações finais}

Sendo a leitura literária um meio pelo qual o aluno pode progredir, a escola, que é o ambiente para as práticas sociais, tem papel importante no processo de formação do leitor literário. Por isso, a necessidade de a escola romper com os aspectos tradicionais por ela adotados.

Neste artigo, procuramos expor alguns conceitos que estão relacionados às metodologias ativas, explicando desde o seu próprio conceito, o que se entende por intermidialidade, o que é podcast e, mais do que isso, retomando um relato sobre uma experiência vivenciada na prática com o uso desse instrumento. 
O que temos exposto são "nortes", ou, em outras palavras, caminhos que podem vir a ser trilhados na prática docente, conforme as motivações e interesses inerentes à nossa formação profissional. Como citamos anteriormente pelas linhas da BNCC que trouxemos à cena, cabe ao professor - sendo ele o mediador do ensino-aprendizagem -, a tarefa de propiciar ao aluno a formação literária. Mas o que evidenciamos também é que, ao lado deste importante objetivo, o uso de um recurso tecnológico pode ser um adjuvante substantivo. Nesse sentido, se o educador precisa saber selecionar textos que se adequem às expectativas e necessidades dos alunos; saber fazer a migração desse objeto para uma mídia ligada ao cotidiano deles igualmente pode representar um ganho no processo de ensino-aprendizagem, ao proporcionar o contato com uma "linguagem" que the é familiar. Outrossim, se a experiência de trabalho com uma literatura estrangeira, como é o caso da portuguesa, pode causar certo "estranhamento" pelo distanciamento dos alunos com a linguagem ali colocada (de diferentes épocas e estilos), a intermidialidade promove uma aproximação entre um conteúdo aparentemente intransponível para algo que pertence ao mundo/contexto do estudante. Por fim, cabe ainda salientar que o podcast, através da elaboração de seu roteiro de produção, conforme tentamos salientar ao longo deste artigo, exige do discente algo que o coloca no centro da aprendizagem, principalmente pelo fato de que demanda dele o estudo, a leitura e a compreensão de seu objeto literário no processo de adaptação (na intermidialidade propriamente). Certamente proporcionando uma experiência significativa do estudante com a literatura que precisa dominar.

\section{Referências}

ANASTASIOU, L. das G.; ALVES, L. P. Processos de ensinagem na universidade: pressupostos para as estratégias de trabalho em aula. 8. ed. Joinville, SC: Univille, 2009.

BERLEZZI, F. L. C; MACHADO, A. R. Relato de experiência: produção audiovisual como metodologia ativa no ensino- aprendizagem de Literatura Portuguesa. In: CORRADIN, F. M.; ROSA, C. G.; DOMENE, M. G.; DRIVER, R. (Org.). A pesquisa em Literatura Portuguesa Homenagem ao Prof. Francisco Maciel Silveira. São Paulo: Na Raiz, 2020. v. 1, p. 180-200.

BOTTENTUIT JUNIOR, J. B.; COUTINHO, C. P. A educação a distância para a formação ao longo da vida na sociedade do conhecimento. In: BARCA, A.; PERALBO, M.; PORTO, A.; SILVA, B. D.; ALMEIDA, L. (Ed.). Actas do IX Congresso Internacional Galego Português de Psicopedagogia. A Coruña: Universidade da Coruña, 2007. p. 613-623. 
BRASIL. Ministério da Educação. Base Nacional Comum Curricular BNCC. Versão final. Brasília: MEC, 2018.

CLÜVER, C. Intermidialidade. PÓS: Revista do Programa de Pós-Graduação em Artes da EBA/UFMG, v. 1, n. 2, p. 8-23, 2012. Disponível em: https://eba.ufmg.br/revistapos3/index.php/pos/article/view/16. Acesso em: 20 jul. 2020.

LOURENÇO, E. Mitologia da saudade. São Paulo: Companhia das Letras, 1999.

MACHADO, I. A. Texto \& gêneros: fronteiras. In: MACHADO, I. A. Espaços da linguagem. São Paulo: Editora Humanitas, 1999.

MACHADO, I. A. Escola de semiótica - A experiência de Tártu-Moscou para o estudo da cultura. São Paulo: Ateliê Editorial, 2003.

PODPESQUISA 2014. Disponível em: http://www.podpesquisa.com.br/2014/resultado. Acesso em: 20 jan. 2020.

ROY, A. K.; ROY, P. A. Intersection of training and podcasting in adult Education. Australian Journal of Adult Learning, v. 47, n. 3, p. 479-491, nov. 2007.

SANTAELLA, L. Da cultura das mídias à cibercultura: o advento do póshumano. Revista FAMECOS, Porto Alegre, n. 22, p. 23-32, dez. 2003. DOI: https://doi.org/10.15448/19803729.2003.22.3229

STOCK, A. Universidades dos EUA usam podcast para atrair público. 2007. Disponível em: http://tecnologia.terra.com.br/interna/0,,Ol1919883-El4802,00.html. Acesso em: 20 jan. 2020.

VASCONCELLOS, C. dos S. Construção do conhecimento em sala de aula. São Paulo: Libertard, 1994. 